\title{
The association between occupational factors, depression, and health-related quality of life in military women in the Republic of Korea: a cross-sectional study
}

\author{
Eunji Kwon ${ }^{1,2}$, Jeongok Park ${ }^{3^{*}}$, Sue Kim³ and Kyung Hee Lee ${ }^{3}$
}

\begin{abstract}
Background: Health-related quality of life (HRQOL) is an important concept to consider both individuals' ability to manage their daily lives and health status across the lifespan. Despite this variable's importance, there is a lack of clarification on the factors associated with HRQOL, especially for military women. The aim of this study was to examine factors associated with HRQOL of military women in the Republic of Korea (ROK) Army.
\end{abstract}

Methods: This cross-sectional study included 196 participants who were currently within their 5-year service period. HRQOL was measured by the Korean version of the Short-Form 36 Health Survey Questionnaire version 2.0 (SF-36V2), and depression was assessed using the Korean version of the Patient Health Questionnaire-9 (PHQ-9). Differences in HRQOL according to general and occupational factors were analyzed using the independent t-test and analysis of variance (ANOVA). Multiple linear regression analysis was performed to identify factors associated with the HRQOL of women serving as military junior officers.

Results: The mean score for the physical component summary (PCS) of SF-36v2 was $56.0 \pm 5.8$, and that for the mental component summary (MCS) of SF-36v2 was $47.2 \pm 10.0$. For depression, the mean score was $5.4 \pm 5.2$, whereas $19.4 \%$ of the participants scored more than 10 out of 27 points, which means moderate to severe. No variables showed statistically significant relationships with the PCS. However, military women showed a lower score for MCS when they were officers (adjusted $\beta=-3.52 ; 95 \% \mathrm{Cl}=-5.47,-1.58$ ), had higher perceived stress (adjusted $\beta=-0.62,95 \% \mathrm{Cl}=-0.83,-0.41$ ), and a higher score for depression (adjusted $\beta=-0.86,95 \% \mathrm{Cl}=-1.10,-0.63$ ).

Conclusions: Although depression levels were not severe, it was a significant factor of HRQOL. Stress and depression were found to be significant factors associated with the MCS in military women. Therefore, to improve their HRQOL, the ROK Army should provide early screening, intervention, and management program for high-risk military women. In addition, an appropriate organizational atmosphere within the military must be created to promote such programs.

Keywords: Military women, Health-related quality of life, Stress, Depression

*Correspondence: jopark02@yuhs.ac

${ }^{3}$ Mo-Im Kim Nursing Research Institute and College of Nursing, Yonsei University, 50-1 Yonsei-ro, Seodaemun-gu, Seoul 03722, Republic of Korea Full list of author information is available at the end of the article

\section{Introduction}

Military women in the Republic of Korea (ROK) comprise officers and non-commissioned officers serving in the field through voluntary enlistment; the Ministry of National Defense stated that it planned to increase the proportion of female soldiers, who accounted for about original author(s) and the source, provide a link to the Creative Commons licence, and indicate if changes were made. The images or other third party material in this article are included in the article's Creative Commons licence, unless indicated otherwise in a credit line to the material. If material is not included in the article's Creative Commons licence and your intended use is not permitted by statutory regulation or exceeds the permitted use, you will need to obtain permission directly from the copyright holder. To view a copy of this licence, visit http://creativecommons.org/licenses/by/4.0/. The Creative Commons Public Domain Dedication waiver (http://creativeco mmons.org/publicdomain/zero/1.0/) applies to the data made available in this article, unless otherwise stated in a credit line to the data. 
$3.5 \%$ of all military officers in 2010 , to $8.8 \%$ by 2020 [1]. In general, military junior officers are personnel with a service period of less than 5 years, and this group accounts for about $70 \%$ of military officers in their 20s and 30s [2]. This age group encompasses the transition from adolescence to adulthood and is among the healthiest periods in the life cycle [3]. This period is also characterized by extensive variation in individual health promotion activities, such as eating habits and physical activity, depending on the individual's personal choices [4], and in particular, since most female military junior officers are women of childbearing age, they are required to consider aspects of their reproductive health. Accordingly, the Ministry of National Defense is making efforts to create a healthy working environment and to establish policies for military women by identifying high-priority health problems and vulnerable groups through comprehensive studies of overall health conditions, medical institution use, and women's health [5].

As the definition of health has been extended from simply the absence of disease to the concept of complete well-being in recent years, researchers have taken an increasing interest in health-related quality of life (HRQOL), a concept that considers an individual's ability to manage his or her daily life and a person's health status across the lifespan [6, 7]. Measurements of HRQOL are important methodological tools for routine monitoring, especially when providing healthcare for vulnerable groups [8]. With the recent increase in interest in HRQOL, numerous studies have been conducted in diverse populations differing in terms of gender and age groups $[6,9,10]$. Those studies have shown that high self-efficacy, stress management, formation of a desirable eating attitude, and appropriate physical activity are important factors that improve HRQOL at the individual level $[3,6,9]$.

For military women serving in the ROK Army, it has been confirmed that distinctive characteristics of the armed forces, such as rank, length of service, working hours, number of overtime hours, and working areas, are related to health-promoting activities [11]. These results suggest that both systematic health care policies at the organizational level and individual issues should be considered when formulating strategies for improving HRQOL of Korean military women [11]. In addition, since most Korean military women are in their childbearing age, specific attention should be paid to aspects of reproductive health $[9,11]$. Therefore, for establishing strategies to improve the HRQOL of Korean military women, both individual-level health promotion activities and women's normal health problems according to their life cycle should be considered in light of the distinctive features of the military environment. Nevertheless, there was a lack of research that explored the factors that affect soldiers' HRQOL [10, 11], especially with appropriate consideration of both individual health promotion activities and women's life cycle in the unique environment of the military.

The conceptual framework for the current study was developed based on the comprehensive literature review (Fig. 1). The variables of physical activity, stress, attitude to eating, self-efficacy, and depression, as well as general and occupational characteristics such as age, education, marital status, age at menarche, delivery experience, rank, and branch were included in the conceptual framework to identify factors associated with the HRQOL. The purpose of this study was to explore the level of HRQOL and identify factors associated with HRQOL among military women serving in the ROK Army. Specifically, we hypothesized that military women's physical activity, stress, attitude to eating, self-efficacy, depression, and occupational characteristics will be significantly associated with their HRQOL.

\section{Materials and methods \\ Study design and sample}

This cross-sectional study was conducted in November 2019. The inclusion criteria were military women who currently served in the ROK Army with a service period within 5 years and voluntarily chose to participate in this study after receiving an explanation of the purposes and goals of the research. The exclusion criteria were military women who currently served in the ROK Navy, Marine Corps, and Air Forces because their working area and occupational environment were different from those of the Army. The sample size was calculated using G*Power 3.1.9.7. To perform a multiple linear regression analysis, the sample size with a significance level of 0.05 , power of 0.80 , effect size (medium) of 0.15 , and 22 independent variables was calculated as at least 163 and, after considering the attrition rate of $20 \%$, was calculated as 196 [12]. A total of 231 military women initially accessed the online website to participate in the study, but 35 women were excluded because they did not meet the inclusion criteria (Fig. 2). Therefore, 196 women who completed the survey were included for the data analysis. The flowchart for sample recruitment was illustrated in Fig. 2.

Because military women work throughout the nation and the proportion of military women in each division is only approximately $5 \%$, the survey was conducted in an online and mobile format. By cooperating with official announcements and text messages, we encouraged participation in the survey. The recruitment notice included a description of the purpose and methods of this study, the conditions for participants, the benefits and risks of this study, the discontinuation of voluntary 


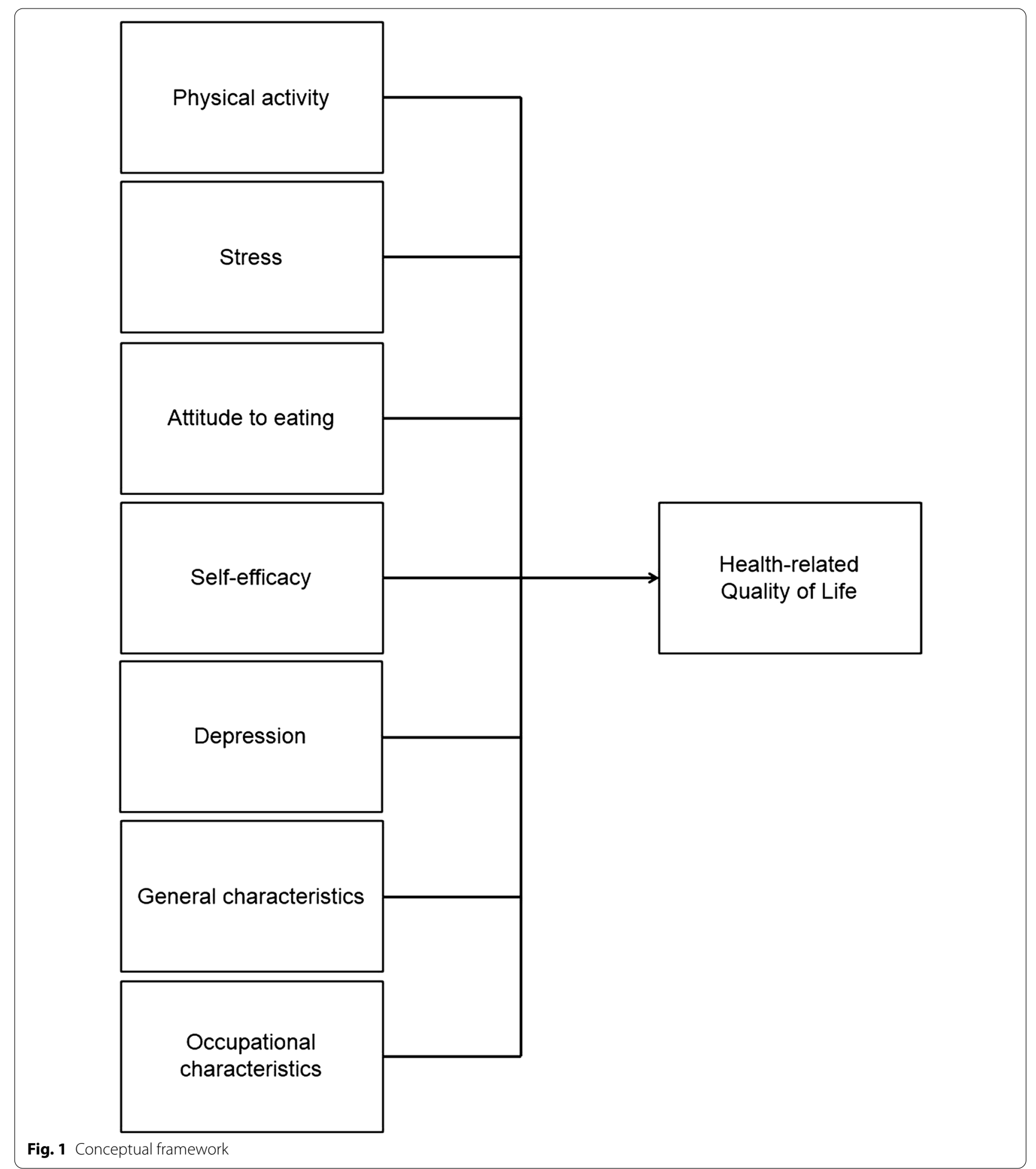

participation, and the assurance of anonymity for the study participants.

Those who fulfilled the inclusion criteria and voluntarily agreed to participate in the study were provided a link for the online survey. Screening questions were also presented on the first screen of the online survey to ensure that participants met the selection criteria. If all criteria were met, the participant completed the survey after viewing and an explanation stating that completing the survey was considered as constitute agreement to 


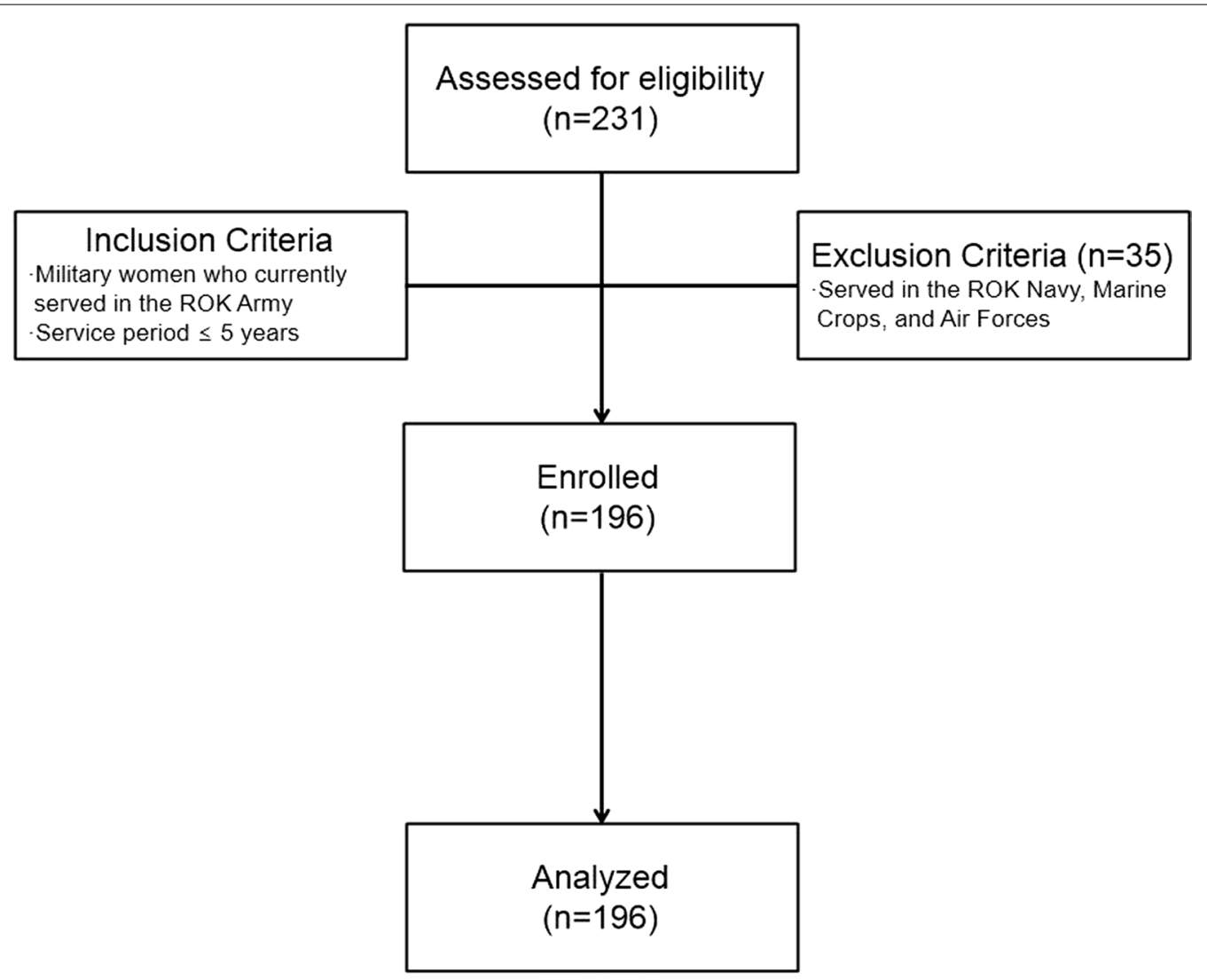

Fig. 2 Flow-chart of this study

participate in this study. The participants who completed the survey received approximately \$3(USD) gift cards.

The average response time for this survey was about $15 \mathrm{~min}$. In accordance with institutional review board (IRB) approval (IRB approval number: Y-2019-0162), a protocol was put in place to ensure that the researcher was notified of responses anonymously and that the respondents' phone numbers were not transmitted to the researcher. In order to prevent duplicate responses from the same participants and to ensure that the survey was not distributed beyond the intended participants, researchers monitored survey participation twice a day.

\section{Measurement}

The research instrument was a self-reported survey questionnaire that consisted of 116 questions, including 36 questions about HRQOL, 7 questions about physical activity, 10 questions about stress, 26 questions about attitudes to eating, 10 questions about self-efficacy, 9 questions about depression, and 18 questions about general and occupational characteristics. The original authors approved the use of the relevant tools, the validity and reliability of which have been demonstrated in previous studies.

\section{Dependent variables Health-related quality of life}

HRQOL was the dependent variable of this study. The Korean version of the Short-Form 36 Health Survey Questionnaire version 2.0 (SF-36v2) is a self-evaluation scale used to measure HRQOL [13], and consists of 36 items that measure eight health domains: physical function, role limitations due to physical problems, bodily pain, general health perception, vitality, social functioning, role limitations related to emotional problems, and general mental health. The score for each domain ranges from 0 to 100, with higher scores indicating better HRQOL. These domains can be categorized into the physical component summary (PCS) and mental component summary (MCS). PCS and MCS scores are represented on a standardized scale (as a $\mathrm{T}$ score with a mean of 50 and standard deviation (SD) of 10). The internal consistency of the PCS and MCS was quantified using Cronbach's $\alpha$, with values of 0.78 and 0.60 , respectively. 


\section{Independent variables}

\section{Physical activity}

The Korean version of the International Physical Activity Questionnaire (IPAQ) was used to estimate participants' level of physical activity during the previous 7 days [14]. The items of the IPAQ are structured to provide a domain-specific score for walking, moderate-intensity, and vigorous-intensity activity. The results are presented as the estimated energy expenditure in metabolic equivalent-minutes per week (MET hours/week). The number of MET hours/week for a specific activity is computed by multiplying the MET value for the activity (3.3 for walking, 4.0 for moderate-intensity activity, and 8.0 for vigorous-intensity activity) by the number of hours spent on that activity [14].

\section{Stress}

The Korean version of the Perceived Stress Scale (PSS) was applied to assess the degree to which respondents perceived their lives to be unpredictable and uncontrollable over the past month [15]. The PSS consists of 10 items, and higher scores indicate more severe stress. The internal consistency of the questionnaire was confirmed by a Cronbach's $\alpha$ of 0.88 in this study.

\section{Attitude to eating}

Disordered eating in participants was assessed using the Korean version of Eating Attitudes Test-26 (EAT-26) questionnaire. The EAT-26 questionnaire includes 26 items in 4 domains: (1) self-control of eating and bulimic symptom, (2) preoccupation with being thinner, (3) food preoccupation, and (4) dieting [16, 17]. Each item is responded to on a 6-point Likert scale, but not all positions on the scale are scored. Each item is given a score of zero for 'sometimes', 'rarely', and 'never'; a score of 1 for 'often'; a score of 2 for 'usually'; and a score of 3 for 'always.' The total score ranges from 0 to 78 , with higher scores indicating that a respondent is at a higher risk of eating disorders. The internal consistency of the questionnaire was shown by a Cronbach's $\alpha$ of 0.87 in this study.

\section{Self-efficacy}

The Korean adaptation of the General Self-Efficacy Scale was used to measure self-efficacy [18]. It consists of 10 items concerning self-confidence and is measured on a 4-point Likert scale. Each question was answered with scores from 'not at all true' (1) to 'exactly true' (4). The total score ranges from 10 to 40, with higher scores indicating better self-efficacy. The internal consistency of the questionnaire was demonstrated by a Cronbach's $\alpha$ of 0.89 in this study.

\section{Depression}

The Korean version of the Patient Health Questionnaire-9 (PHQ-9) was applied to assess the degree of depression [19]. PHQ-9 is a self-evaluation scale used to measure mental health at primary health care centers [20]. It consists of 9 items assessing the frequency with which patients have experienced depressive thoughts or feelings over the prior 2 weeks. The severity of depressive disorder is considered mild for scores ranging from 5 to 9 and moderate to severe for score from 10 or more [19]. The internal consistency of the questionnaire was shown by a Cronbach's $\alpha$ of 0.90 in this study.

\section{General and occupational characteristics}

The following general characteristics were collected: age, body mass index (BMI), religion, education level, marital status, living with spouse, age at menarche, regularity of the menstrual cycle, length of the menstrual cycle, pregnancy and delivery experience, and history of oral contraception use. BMI classification used for Asian populations [21]. The occupational characteristics were rank, branch, duration of service, working area, duty time, service type, and number of overtime days.

\section{Data analysis}

The collected data were statistically processed using the SPSS version 25 (IBM Corp., Armonk, NY, USA). Descriptive statistics were calculated for participants' characteristics. The differences in HRQOL were analyzed using the independent t-test and analysis of variance (ANOVA). Multiple linear regression analysis was conducted to identify factors significantly associated with HRQOL among military women. A two-tailed probability value of $p<0.05$ was considered to indicate statistical significance.

\section{Results \\ Differences in health-related quality of life according to participants' general and occupational characteristics}

Table 1 presents participants' general and occupational characteristics. The mean $\pm \mathrm{SD}$ age of the participants was $25.2 \pm 2.2$ years, and their mean \pm SD BMI was $21.8 \pm 2.3 \mathrm{~kg} / \mathrm{m}^{2}$, with $145(74.0 \%)$ participants having a $\mathrm{BMI}$ in the normal range $\left(18.5\right.$ to $\left.23.0 \mathrm{~kg} / \mathrm{m}^{2}\right)$ [21]. 24 $(12.2 \%)$ women were married, and 16 (66.7\%) of them lived with their spouses or children. All of the participants responded that they currently had menstrual cycles and 48 (26.5\%) indicated that they experienced menstrual irregularity. Approximately one-quarter of participants had taken oral contraceptive pills (25.5\%). Moreover, on average, oral contraceptive pills were taken for $5.1 \pm 6.7$ months. The most common reason for taking oral contraceptive pills was for menstrual suppression 
Table 1 Differences in health-related quality of life according to general and occupational characteristics $(\mathrm{N}=196)$

\begin{tabular}{|c|c|c|c|c|c|c|}
\hline \multirow[t]{3}{*}{ Variable } & \multirow[t]{3}{*}{ Categories } & \multirow{3}{*}{$\begin{array}{l}\mathbf{n}(\%) \text { or } \\
\text { Mean } \pm \text { SD }\end{array}$} & \multicolumn{4}{|c|}{ Health-related quality of life } \\
\hline & & & $\begin{array}{l}\text { Physical } \\
\text { component } \\
\text { summary }\end{array}$ & $\begin{array}{l}\text { tor } F \text { or } r \\
(p)\end{array}$ & $\begin{array}{l}\text { Mental } \\
\text { component } \\
\text { summary }\end{array}$ & $\begin{array}{l}\text { t or } \mathrm{F} \text { or } \mathrm{r} \\
(p)\end{array}$ \\
\hline & & & Mean \pm SD & & Mean \pm SD & \\
\hline \multicolumn{7}{|l|}{ General characteristics } \\
\hline Age (years) & & $25.2 \pm 2.2$ & & $0.05(0.519)$ & & $0.14(0.056)$ \\
\hline \multirow[t]{4}{*}{ Body mass index $\left(\mathrm{kg} / \mathrm{m}^{2}\right)$} & $<18.5$ & $7(3.6)$ & $59.8 \pm 2.8$ & $2.68(\mathbf{0 . 0 4 8})^{\dagger}$ & $46.0 \pm 8.2$ & $0.07(0.978)$ \\
\hline & $18.5-22.9$ & $145(74.0)$ & $55.8 \pm 5.6$ & & $47.3 \pm 9.7$ & \\
\hline & $23.0-24.9$ & $21(10.7)$ & $57.7 \pm 4.3$ & & $46.6 \pm 11.3$ & \\
\hline & $\geq 25$ & $23(11.7)$ & $54.0 \pm 7.6$ & & $47.4 \pm 11.9$ & \\
\hline \multirow[t]{2}{*}{ Religion } & Yes & $101(51.5)$ & $55.4 \pm 5.8$ & $1.33(0.184)$ & $47.2 \pm 9.9$ & $-0.13(0.896)$ \\
\hline & No & $95(48.5)$ & $56.5 \pm 5.7$ & & $47.1 \pm 10.3$ & \\
\hline \multirow[t]{3}{*}{ Education } & $\leq$ High school & $9(4.5)$ & $58.2 \pm 6.1$ & $1.16(0.316)$ & $45.3 \pm 10.0$ & $0.43(0.648)$ \\
\hline & College & $45(23.0)$ & $55.2 \pm 5.5$ & & $48.2 \pm 10.0$ & \\
\hline & $\geq$ University & $142(72.5)$ & $56.0 \pm 5.8$ & & $46.9 \pm 10.1$ & \\
\hline \multirow[t]{2}{*}{ Marital status } & Unmarried & $172(87.8)$ & $55.8 \pm 5.9$ & $-1.06(0.290)$ & $46.6 \pm 9.7$ & $-2.22(\mathbf{0 . 0 2 7})$ \\
\hline & Married & $24(12.2)$ & $57.1 \pm 4.7$ & & $51.4 \pm 11.6$ & \\
\hline \multirow[t]{2}{*}{ Living situation $(n=24)$} & With spouse & $16(66.7)$ & $58.6 \pm 2.9$ & $-1.94(0.086)$ & $56.4 \pm 4.6$ & $-2.77(\mathbf{0 . 0 2 5})$ \\
\hline & Without spouse & $8(33.3)$ & $54.1 \pm 6.2$ & & $41.3 \pm 15.0$ & \\
\hline Age at menarche (years) & & $13.2 \pm 1.5$ & & $-0.05(0.476)$ & & $0.01(0.914)$ \\
\hline \multirow[t]{2}{*}{ Menstrual cycle $(n=181)$} & Regular & $133(73.5)$ & $56.3 \pm 5.6$ & $0.98(0.327)$ & $47.2 \pm 10.6$ & $0.14(0.891)$ \\
\hline & Irregular & $48(26.5)$ & $55.4 \pm 6.1$ & & $47.0 \pm 9.2$ & \\
\hline Length of menstrual cycle $(n=181)$ & & $34.6 \pm 26.8$ & & $0.06(0.399)$ & & $0.01(0.914)$ \\
\hline \multirow[t]{2}{*}{ Pregnancy experience } & Yes & $10(5.1)$ & $56.4 \pm 5.0$ & $-0.25(0.806)$ & $51.4 \pm 8.7$ & $-1.38(0.169)$ \\
\hline & No & $186(94.9)$ & $55.9 \pm 5.8$ & & $46.9 \pm 10.1$ & \\
\hline \multirow[t]{2}{*}{ Number of pregnancies $(n=10)$} & 1 & $7(70.0)$ & $56.6 \pm 5.5$ & $0.20(0.849)$ & $48.4 \pm 8.8$ & $-2.99(\mathbf{0 . 0 2 3})$ \\
\hline & 2 or more & $3(30.0)$ & $55.9 \pm 4.4$ & & $58.5 \pm 0.8$ & \\
\hline \multirow[t]{2}{*}{ Delivery experience } & Yes & $8(4.1)$ & $56.1 \pm 5.4$ & $-0.08(0.933)$ & $52.5 \pm 9.4$ & $-1.53(0.127)$ \\
\hline & No & $188(95.9)$ & $55.9 \pm 5.8$ & & $46.9 \pm 10.0$ & \\
\hline Age at first birth $(n=8)$ & & $26.5 \pm 2.5$ & & $-0.20(0.638)$ & & $-0.58(0.134)$ \\
\hline \multirow[t]{2}{*}{ History of oral contraceptive use } & Yes & $50(25.5)$ & $55.4 \pm 5.8$ & $0.81(0.419)$ & $48.6 \pm 9.6$ & $-1.15(0.251)$ \\
\hline & No & $146(74.5)$ & $56.1 \pm 5.8$ & & $46.7 \pm 10.2$ & \\
\hline $\begin{array}{l}\text { Duration of oral contraceptive use } \\
\text { (month) }\end{array}$ & & $5.1 \pm 6.7$ & & $-0.04(0.669)$ & & $-0.15(0.159)$ \\
\hline \multicolumn{7}{|l|}{ Occupational characteristics } \\
\hline \multirow[t]{2}{*}{ Rank } & Non-commissioned officer & $69(35.2)$ & $55.5 \pm 6.1$ & $-0.88(0.382)$ & $49.4 \pm 9.6$ & $2.39(\mathbf{0 . 0 1 8})$ \\
\hline & Officer & $127(64.8)$ & $56.2 \pm 5.6$ & & $45.9 \pm 10.1$ & \\
\hline \multirow[t]{3}{*}{ Branch } & Combat & $77(39.3)$ & $56.1 \pm 5.8$ & $0.19(0.830)$ & $47.4 \pm 10.4$ & $0.05(0.949)$ \\
\hline & Technical \& Administrative & $41(20.9)$ & $55.5 \pm 6.0$ & & $47.2 \pm 10.6$ & \\
\hline & Specialized & $78(39.8)$ & $56.0 \pm 5.7$ & & $46.9 \pm 9.4$ & \\
\hline Duration of service (month) & & $32.7 \pm 15.7$ & & $0.10(0.171)$ & & $0.12(0.088)$ \\
\hline \multirow[t]{2}{*}{ Working area } & Urban area & $94(48.0)$ & $56.2 \pm 4.8$ & $0.56(0.576)$ & $48.0 \pm 9.2$ & $1.17(0.243)$ \\
\hline & Rural area & $102(52.0)$ & $55.7 \pm 6.6$ & & $46.4 \pm 10.7$ & \\
\hline \multirow[t]{3}{*}{ Duty time } & Day time & $164(83.7)$ & $56.2 \pm 5.7$ & $0.82(0.444)$ & $47.2 \pm 10.2$ & $1.03(0.358)$ \\
\hline & Night time & $9(4.6)$ & $54.7 \pm 7.4$ & & $42.9 \pm 12.6$ & \\
\hline & Shift work & $23(11.7)$ & $54.8 \pm 5.8$ & & $48.5 \pm 7.5$ & \\
\hline \multirow[t]{3}{*}{ Service type } & Short-term service & $80(40.8)$ & $55.4 \pm 6.4$ & $0.96(0.385)$ & $46.6 \pm 9.9$ & $0.23(0.793)$ \\
\hline & Extended service & $44(22.5)$ & $55.8 \pm 5.4$ & & $47.5 \pm 10.4$ & \\
\hline & Long-term service & $72(36.7)$ & $56.7 \pm 5.3$ & & $47.6 \pm 10.0$ & \\
\hline Number of overtime days & & $7.7 \pm 8.2$ & & $-0.06(0.391)$ & & $-0.16(\mathbf{0 . 0 2 3 )}$ \\
\hline
\end{tabular}


during dispatch and training (42.0\%), followed by temporary contraception $(32.0 \%)$ and therapeutic purposes for a disease (26.0\%). There were 69 (35.2\%) non-commissioned officers and 127 (64.8\%) officers, distributed among combat, technical and administrative, and specialized branches (39.3\%, 20.9\%, and 39.8\%, respectively). Average overtime per month was $7.7 \pm 8.2$ days.

In this study, PCS and MCS scores are represented on a standardized scale (as a $\mathrm{T}$ score with a mean of 50 and SD of 10). Significant differences were found in the PCS score according to BMI $(\mathrm{F}=2.68, p=0.048)$. However, multiple comparisons with Bonferroni procedures resulted in no significant differences between groups. The married military women reported significantly higher MCS scores than the unmarried military women (51.4 and 46.6, respectively, $p=0.027$ ). Among the married military women, the MCS score was significantly different according to whether respondents lived with their spouses $(t=-2.77, p=0.025)$. Significant differences in the MCS score were found according to rank, with officers reporting significantly lower scores than non-commissioned officers (45.9 and 49.4, respectively, $p=0.018$ ). A higher number of overtime days per month was associated with a lower MCS score $(\mathrm{r}=-0.16, p=0.023)$.

\section{Descriptive statistics for research variables}

Table 2 presents descriptive statistics for HRQOL and the other variables evaluated in the questionnaire. The scores of the two main domains, PCS and MCS, were 56.0 \pm 5.8 and $47.2 \pm 10.0$, respectively. Each domain was converted to a score of $0-100$ points, with higher scores indicating better HRQOL. The highest score was reported for the physical function domain $(92.2 \pm 14.2)$ and the lowest score for vitality $(58.5 \pm 20.2)$.

When the participants were categorized according to the criteria for IPAQ, 37 (18.9\%) participants were inactive, 96 (49.0\%) were minimally physical active, and 63 (32.1\%) engaged in a health-enhancing level of physical activity. The mean scores for perceived stress, attitudes to eating, and self-efficacy were $18.0 \pm 6.2,9.4 \pm 9.3$, and $29.0 \pm 4.2$, respectively. The mean score of depression was $5.4 \pm 5.2$, and $38(19.4 \%)$ of the participants had a total score of more than 10 (moderate to severe).

\section{Factors associated with health-related quality of life}

Table 3 presents the results of multiple linear regression to identify factors associated with the participants' HRQOL. An independent t-test and one-way ANOVA were performed to confirm statistically significant variables of HRQOL among the general and occupational characteristics (Table 1). Among the significant variables, living situation and number of pregnancies were not included in the multiple linear regression model because whole participants did not respond to those questions. Furthermore, the variables suggested in the conceptual framework such as physical activity, stress, attitude to eating, self-efficacy, and depression were included in the multiple linear regression model, as previous studies found an association with HRQOL. The multicollinearity between the independent variables that were included in the multiple linear regression was examined. As a result, the overall variance inflation factor was less than 10 , confirming the independence between independent variables.

The values of $R^{2}$ and adjusted $R^{2}$, which indicate the goodness of fit of the model [22], were 0.091 and 0.047 for PCS and 0.625 and 0.607 for MCS, respectively. No factors had a statistically significant effect on PCS scores, while rank, perceived stress, and depression were all statistically significantly associated with MCS scores.

The average MCS score of officers was 3.52 lower than that of non-commissioned officers (adjusted $\beta=-3.52$; $95 \% \mathrm{CI}=-5.47,-1.58$ ). Higher levels of perceived stress were associated with lower MCS scores (adjusted $\beta=-0.62,95 \% \mathrm{CI}=-0.83,-0.41$ ); each 1 -unit increase in stress led to a 0.62 -point decrease in the MCS score after controlling for other variables $(p<0.001)$. And higher levels of depression were associated with lower MCS scores (adjusted $\beta=-0.86,95 \%$ CI $=-1.10$, $-0.63)$.

\section{Discussion}

The findings of this study provide important information about HRQOL among military women serving in the ROK Army. Approximately 7,550 military women currently serve in the ROK Army [23]. Although the number of military women in the ROK is increasing, research on them remains insufficient [5]. Furthermore, limited research has focused exclusively on particular rank or branch; therefore, this study is meaningful in that it provides basic data for understanding HRQOL among military women in the Army, who account for $70 \%$ of the ROK whole military women [5].

The current study showed that the PCS score for military women was 56.0 points, which is higher than the score of 50.7 points reported for the ROK female undergraduates of the same age and the score of 53.5 points reported for the US military women of the same age [9, 24]. In previous studies, PCS was associated with being married, higher educational attainment, and higher military rank among US military women [24], and lower BMI and higher exercise frequency among Croatian university students [25]. However, no variables significantly associated with the PCS in this study. This is most likely 
Table 2 Descriptive statistics of the research variables $(N=196)$

\begin{tabular}{|c|c|c|c|}
\hline Variables & Categories & Possible range & $\begin{array}{l}\mathrm{n}(\%) \text { or } \\
\text { Mean } \pm \text { SD }\end{array}$ \\
\hline \multicolumn{4}{|c|}{ Health-related quality of life } \\
\hline \multirow[t]{5}{*}{ PCS } & & & $56.0 \pm 5.8$ \\
\hline & Physical function & $0-100$ & $92.2 \pm 14.2$ \\
\hline & Role limitations due to physical problems & $0-100$ & $88.5 \pm 16.6$ \\
\hline & Bodily pain & $0-100$ & $80.8 \pm 20.3$ \\
\hline & General health perception & $0-100$ & $73.5 \pm 19.0$ \\
\hline \multirow[t]{5}{*}{ MCS } & & & $47.2 \pm 10.0$ \\
\hline & Vitality & $0-100$ & $58.5 \pm 20.2$ \\
\hline & Social functioning & $0-100$ & $84.2 \pm 19.2$ \\
\hline & Role limitations due to emotional problems & $0-100$ & $83.0 \pm 21.8$ \\
\hline & General mental health & $0-100$ & $69.5 \pm 19.6$ \\
\hline \multirow[t]{3}{*}{ Physical activity } & Category 1 (inactive) & & $37(18.9)$ \\
\hline & Category 2 (minimal physical activity) & & $96(49.0)$ \\
\hline & Category 3 (health-enhancing physical activity) & & $63(32.1)$ \\
\hline \multirow[t]{5}{*}{ MET (min/week) } & Total physical activity & & $2915.5 \pm 3431.0$ \\
\hline & Walking activity & & $1460.4 \pm 2373.0$ \\
\hline & Moderate activity & & $495.1 \pm 813.1$ \\
\hline & Vigorous activity & & $960.0 \pm 1226.0$ \\
\hline & Sitting activity per day (min) & & $370.3 \pm 250.8$ \\
\hline Perceived stress & & $0-40$ & $18.0 \pm 6.2$ \\
\hline \multirow[t]{5}{*}{ Attitudes to eating } & & $0-78$ & $9.4 \pm 9.3$ \\
\hline & Self-control of eating and bulimic symptom & & $2.4 \pm 3.9$ \\
\hline & Preoccupation with being thinner & & $4.1 \pm 4.0$ \\
\hline & Food preoccupation & & $0.9 \pm 1.5$ \\
\hline & Dieting & & $1.9 \pm 2.7$ \\
\hline Self-efficacy & & $10-40$ & $29.0 \pm 4.2$ \\
\hline \multirow[t]{4}{*}{ Depression } & & $0-27$ & $5.4 \pm 5.2$ \\
\hline & 0-4 (Normal) & & $106(54.1)$ \\
\hline & 5-9 (Mild depression) & & $52(26.5)$ \\
\hline & $10 \leq$ (Moderate to severe depression) & & $38(19.4)$ \\
\hline
\end{tabular}

PCS: physical component summary, MCS: mental component summary, MET: metabolic equivalent

because military women in the ROK Army who participated in the current study engage in individual health promotion behaviors through regular physical training and medical check-ups every year and receive systematic health management.

The average MCS score was 47.2 points; although this value is higher than the 45.3 points reported for the ROK female undergraduates [9], it is lower than 51.0 points for the US military women of the same age [24]. Regarding the factors associated with MCS, officers had a significantly lower score for MCS than non-commissioned officers. This may reflect the differences in duty characteristics between officers and non-commissioned officers [26]. In addition, officers are promoted through a pyramid structure, which poses difficulties in terms of competitiveness, a discriminatory retirement age, a lack of job security, and individual military professional development [27].
Stress and depression were also known to have a negative effect on MCS, as this study has confirmed [26, 28]. Therefore, further research is needed to improve the mental aspect of HRQOL among military women in the ROK Army. In a previous study [26], the quality of life of married military women was lower when they were not living with their families, had no support system, or experienced high stress in the workplace. These results suggest that working conditions need to be addressed in order to improve HRQOL among military women in the ROK Army. Currently, the ROK Army operates a joint childcare center to support work-family balance and strives to resolve psychological conflicts that cause stress and depression for military women by securing replacement personnel for those who have taken leave [23]. Regarding the negative effect of depression on the MCS in the current study, this result is consistent with previous 
Table 3 Factors associated with health-related quality of life ( $N=196)$

\begin{tabular}{|c|c|c|c|c|}
\hline \multirow[t]{3}{*}{ Variable } & \multicolumn{4}{|c|}{ Health-related quality of life } \\
\hline & \multicolumn{2}{|c|}{ Physical Component Summary } & \multicolumn{2}{|c|}{ Mental Component Summary } \\
\hline & $\begin{array}{l}\text { Crude } \beta \\
{[95 \% \mathrm{Cl}]}\end{array}$ & $\begin{array}{l}\text { Adjusted } \beta \\
{[95 \% \mathrm{Cl}]}\end{array}$ & $\begin{array}{l}\text { Crude } \beta \\
{[95 \% \mathrm{Cl}]}\end{array}$ & $\begin{array}{l}\text { Adjusted } \beta \\
{[95 \% \mathrm{Cl}]}\end{array}$ \\
\hline \multicolumn{5}{|l|}{ General and occupational characteristics } \\
\hline $\begin{array}{l}\text { Marital status } \\
\text { (reference }=\text { unmarried) }\end{array}$ & $\begin{array}{l}1.33 \\
{[-1.15,3.82]}\end{array}$ & $\begin{array}{l}0.68 \\
{[-1.83,3.19]}\end{array}$ & $\begin{array}{l}4.82 \\
{[0.55,9.09]}\end{array}$ & $\begin{array}{l}0.71 \\
{[-2.09,3.51]}\end{array}$ \\
\hline $\begin{array}{l}\text { Military rank } \\
\text { (reference = non-commissioned officer) }\end{array}$ & $\begin{array}{l}0.76 \\
{[-0.95,2.46]}\end{array}$ & $\begin{array}{l}1.20 \\
{[-0.54,2.95]}\end{array}$ & $\begin{array}{l}-3.55 \\
{[-6.47,-0.62]}\end{array}$ & $\begin{array}{l}-3.52 \\
{[-5.47,-1.58]}\end{array}$ \\
\hline Number of overtime days & $\begin{array}{l}-0.04 \\
{[-0.14,0.06]}\end{array}$ & $\begin{array}{l}-0.05 \\
{[-0.16,0.05]}\end{array}$ & $\begin{array}{l}-0.20 \\
{[-0.37,-0.03]}\end{array}$ & $\begin{array}{l}-0.03 \\
{[-0.15,0.08]}\end{array}$ \\
\hline \multicolumn{5}{|l|}{$\begin{array}{l}\text { Physical activity } \\
\text { (reference=Category 2; minimal physical activity) }\end{array}$} \\
\hline Category 1 (inactive) & $\begin{array}{l}-0.85 \\
{[-2.93,1.23]}\end{array}$ & $\begin{array}{l}-0.29 \\
{[-2.50,1.93]}\end{array}$ & $\begin{array}{l}-2.28 \\
{[-5.89,1.33]}\end{array}$ & $\begin{array}{l}-0.85 \\
{[-3.32,1.62]}\end{array}$ \\
\hline Category 3 (health-enhancing physical activity) & $\begin{array}{l}0.74 \\
{[-1.00,2.49]}\end{array}$ & $\begin{array}{l}1.35 \\
{[-0.57,3.27]}\end{array}$ & $\begin{array}{l}0.19 \\
{[-2.85,3.22]}\end{array}$ & $\begin{array}{l}0.37 \\
{[-1.77,2.51]}\end{array}$ \\
\hline Perceived stress & $\begin{array}{l}-0.21 \\
{[-0.34,-0.08]}\end{array}$ & $\begin{array}{l}-0.09 \\
{[-0.28,0.09]}\end{array}$ & $\begin{array}{l}-1.11 \\
{[-1.28,-0.95]}\end{array}$ & $\begin{array}{l}-0.62 \\
{[-0.83,-0.41]}\end{array}$ \\
\hline Attitudes to eating & $\begin{array}{l}-0.11 \\
{[-0.19,-0.02]}\end{array}$ & $\begin{array}{l}-0.08 \\
{[-0.18,0.02]}\end{array}$ & $\begin{array}{l}-0.33 \\
{[-0.48,-0.19]}\end{array}$ & $\begin{array}{l}-0.02 \\
{[-0.13,0.09]}\end{array}$ \\
\hline Self-efficacy & $\begin{array}{l}0.25 \\
{[0.05,0.44]}\end{array}$ & $\begin{array}{l}0.07 \\
{[-0.15,0.30]}\end{array}$ & $\begin{array}{l}0.80 \\
{[0.48,1.12]}\end{array}$ & $\begin{array}{l}-0.02 \\
{[-0.27,0.23]}\end{array}$ \\
\hline Depression & $\begin{array}{l}-0.23 \\
{[-0.39,-0.08]}\end{array}$ & $\begin{array}{l}-0.08 \\
{[-0.29,0.13]}\end{array}$ & $\begin{array}{l}-1.37 \\
{[-1.56,-1.18]}\end{array}$ & $\begin{array}{l}-0.86 \\
{[-1.10,-0.63]}\end{array}$ \\
\hline$R^{2}$ & - & 0.091 & - & 0.625 \\
\hline Adjusted R ${ }^{2}$ & - & 0.047 & - & 0.607 \\
\hline$F(p)$ & - & $2.07(0.035)$ & - & $34.48(<0.001)$ \\
\hline
\end{tabular}

95\% Cl: 95\% Confidence interval

studies [29]. In the US military, based on the National Defense Authorization Act, which has been strengthened since 2012, the Army has been required to perform mandatory screening tests for all soldiers each year through existing regular medical check-ups [30]. Considering that twice as many female officers are depressed as civilians of the same age, and that female officers have higher depression scores than male officers $[29,31]$, it should be a priority to identify vulnerable groups through depression screening tests. To manage high-risk groups, the ROK Army needs to pay attention to the identification and systematic management of depression where indicated.

In conclusion, the ROK Army should continue to seek various ways to improve the MCS in order to resolve the mental difficulties faced by military women. There is currently no separate mental health program for military women in the ROK Army. Existing mental health programs focus on post-traumatic stress disorder [32], as such, insufficient research and interventions have been implemented to improve the MCS as part of HRQOL. Furthermore, different factors influence quality of life between male soldiers and female officers, including social support, adjustment to military service, physical environment, and health behaviors [33].

Our research has the following limitations. First, it is difficult to determine causality because this study is based on cross-sectional data obtained from a survey. Reporting bias may have been present because all variables were measured by self-report questionnaires from respondents. Second, because the participants were rewarded with gift cards, these findings may cause extrinsic incentives bias. Third, because this study adopted a convenience sampling method and one of the inclusion criteria was only women who had served in the military for less than 5 years, the participants in the current study were not representative of the ROK Army women. Therefore, the results of this study should be interpreted with caution. Finally, future studies that can validate a theoretical framework could further confirm the variables and their relationships.

Despite these limitations, this study has the following strengths. First, in contrast to previous studies conducted mainly among male soldiers, this study assessed HRQOL and analyzed the factors that influenced it among military 
women in the ROK Army. Second, occupational and female-specific characteristics were considered in addition to general characteristics. For women, it is meaningful to consider these factors because psychological well-being is closely related with employment, marriage, pregnancy, and childcare, necessitating individualized research and interventions [34]. Third, we identified factors with negative and positive effects on the MCS. These findings are helpful in identifying which interventions should be implemented to improve the MCS.

\section{Conclusion}

This study was conducted to identify factors associated with HRQOL among military women in the ROK Army. Stress and depression were found to be significant factors associated with the MCS. Therefore, we suggest that the ROK Army should provide early screening, intervention, and management for groups of high-risk military women. First, programs are needed to identify and manage risk factors that cause stress, and an appropriate organizational atmosphere within the military must be created to promote such training programs. Second, depression screening tests should be required for early management by classifying individuals at a high-risk of depression as a vulnerable group. Finally, given the high proportion of depression, it is suggested that regular HRQOL surveys are needed for members of the ROK Army, including military women.

\begin{abstract}
Abbreviations
$\mathrm{Cl}$ : Confidence interval; ROK: Republic of Korea; HRQOL: Health-related quality of life; IRB: Institutional review board; SF-36v2: Short-Form 36 Health Survey Questionnaire version 2.0; PCS: Physical component summary; MCS: Mental component summary; SD: Standard deviation; IPAQ: International Physical Activity Questionnaire; MET: Metabolic equivalent; PSS: Perceived Stress Scale; EAT-26: Eating Attitudes Test-26; PHQ-9: Patient Health Questionnaire-9; BMI: Body mass index; ANOVA: Analysis of variance.
\end{abstract}

\section{Acknowledgements}

The authors acknowledge the military women who participated in this study for their sincere responses to the survey.

\section{Authors' contributions}

All authors contributed to the study conception and design. Material preparation, data collection and analysis were performed by Eunji Kwon and Jeongok Park. The first draft of the manuscript was written by Eunji Kwon and all authors commented on previous versions of the manuscript. All authors read and approved the final manuscript. This manuscript is a condensed form of the first author's master's thesis from Yonsei University.

\section{Funding}

The research did not receive any specific grant from funding agencies in the public, commercial, or not-for-profit sectors.

\section{Declarations}

\section{Ethics approval and consent to participate}

Our research protocol was submitted for consideration, commenting, guidance and approval to the institutional review board of Yonsei University and accepted before the study began (IRB approval number:Y-2019-0162).
Consent for publication

Not applicable.

\section{Availability of data and materials}

All data generated or The data supporting the findings of this study are not publicly available due to security of the ROK army.

\section{Competing interests}

The authors declare that they have no conflict of interest.

\section{Author details}

${ }^{1}$ College of Nursing, Yonsei University, Seoul, Republic of Korea. ${ }^{2}$ Korea Armed Forces Nursing Academy, Daejeon, Republic of Korea. ${ }^{3} \mathrm{Mo}-\mathrm{Im}$ Kim Nursing Research Institute and College of Nursing, Yonsei University, 50-1 Yonsei-ro, Seodaemun-gu, Seoul 03722, Republic of Korea.

Received: 2 February 2021 Accepted: 20 August 2021

Published online: 14 September 2021

\section{References}

1. Ministry of National Defense. The act on human resources management. http://www.law.go.kr/admRulLsInfoP.do?admRulSeq=2100000006098: Accessed 29 Jan 2021.

2. Hong $C$. The phenomenological analysis of gender equality perception of woman junior officers in the army. Q J Def Policy Stud. 2014:30(3):199-226.

3. Helmer SM, Krämer A, Mikolajczyk RT. Health-related locus of control and health behaviour among university students in North Rhine Westphalia, Germany. BMC Res Notes. 2012;5(1):703-10. https://doi.org/10.1186/ 1756-0500-5-703.

4. Lim HJ, Seo SM. Physical fitness according to body fat and physical activity levels in women university students. J Korean Soc Living Environ Syst. 2010;17(5):557-62.

5. Yoon WS, Seok W, Lee SY, Hwang JS, Ann EG, Choi MS, et al. Health status of ROK military women. J Korean Mil Med Assoc. 2016;47(1):149-72.

6. Kim AK. Yangsaeng and health related quality of life (HRQOL) in middle aged women. Korean J Women Health Nurs. 2010;16(3):297-306. https:// doi.org/10.4069/kjwhn.2010.16.3.297.

7. Lee GH, Kim CH, Shin HC, Park YW, Sung EJ. The relation of physical activity to health related quality of life. Korean J Fam Med. 2007;28(6):451-9.

8. Centers for Disease Control and Prevention. Health-related quality of life (HRQOL). https://www.cdc.gov/hrqol/concept.htm. Accessed 29 Jan 2021

9. Cha BK. factors affecting health-related quality of life in women undergraduates. J Korean Acad Fundam Nurs. 2013;20(4):400-9. https://doi.org/ 10.7739/jkafn.2013.20.4.400.

10. Herrold AA, Pape TL, Li X, Jordan N. Association between alcohol craving and health-related quality of life among veterans with co-occurring conditions. Mil Med. 2017;182(7):e1712-7. https://doi.org/10.7205/ MILMED-D-16-00360.

11. Yoo MR, Choi JA, Hyun HS, Kim KW. A study of health status and health behavior among the military officers in their 20 s and 30s. Korean J Mil Nurs Res. 2009:27(1):122-38.

12. Faul F, Erdfelder E, Lang AG, Buchner A. G*Power 3: a flexible statistical power analysis program for the social, behavioral, and biomedical sciences. Behav Res Methods. 2007;39(2):175-91.

13. Maruish ME. User's manual for the SF-36v2 health survey. 3rd ed. Quality Metric Incorporated: Lincoln; 2011.

14. International Physical Activity Qustionnaire Group. IPAQ scoring protocol. https://sites.google.com/site/theipaq/scoring-protocol. Accessed 29 Jan 2021.

15. Lee J, Shin C, Ko YH, Lim J, Joe SH, Kim S, et al. The reliability and validity studies of the Korean version of the perceived stress scale. Korean J Psychosom Med. 2012;20(2):127-34.

16. Rhee MK, Lee YH, Park SH, Sohn CH, Chung YC, Hong SK, et al. A standardization study of the Korean version of eating attitudes test-26 I: reliability and factor analysis. Korean J Psychosomat Med. 1998;6(2):155-75.

17. Garner DM. Pathogenesis of anorexia nervosa. Lancet. 1993;341:1631-40. https://doi.org/10.1016/0140-6736(93)90768-C. 
18. Lee YM, Schwarzer R, Jerusalem M. Korean adaptation of the general self-efficacy scale. https://userpage.fu-berlin.de/ health/korean.htm. Accessed 29 Jan 2021.

19. Lee S, Huh Y, Kim J, Han C. Finding optimal cut off points of the Korean version of the patient health questionnaire-9 (PHQ-9) for screening depressive disorders. Mood Emot. 2014;12(1):32-6.

20. Spitzer RL, Kroenke K, Williams JB, Patient Health Questionnaire Primare Care Study Group. Validation and utility of a self-report version of PRIMEMD: the PHQ primary care study. JAMA. 1999;282(18):1737-44. https:// doi.org/10.1001/jama.282.18.1737.

21. WHO Expert Consultation. Appropriate body-mass index for Asian populations and its implications for policy and intervention strategies. Lancet. 2004;363(9403):157-63. https://doi.org/10.1016/S0140-6736(03)15268-3.

22. Walker DA, Smith TJ. Nine pseudo $R^{2}$ indices for binary logistic regression models. J Mod Appl Stat Methods. 2016;15(1):848-54. https://doi.org/10. 22237/jmasm/1462077720.

23. Ministry of National Defense. 2018 defense white paper. https://www. mnd.go.kr/cop/pblictn/selectPublicationUser.do?siteld=mnd\&compo nentld=14\&categoryld $=15 \&$ publicationSeq $=835 \&$ pagelndex $=1 \&$ id $=$ mnd_040501000000. Accessed 29 Jan 2021.

24. Smith TC, Zamorski M, Smith B, Riddle JR, LeardMann CA, Wells TS, et al. The physical and mental health of a large military cohort: baseline functional health statues of the millennium cohort. BMC Public Health. 2007;7(1):1-13. https://doi.org/10.1186/1471-2458-7-340

25. Rakovac M, Pedisic Z, Pranic S, Greblo Z, Hodak D. Sociodemographic and lifestyle correlates of health-related quality of life in Croatian University students. Appl Res Qual Life. 2012;8(4):493-509. https://doi.org/10.1007/ s11482-012-9203-9.

26. Oh YR. Effects of work-family conflict and job stress on married female soldiers' quality of life: a case of female officers' in the South Korea Army. Dissertation. Seoul: Seoul National University; 2015
27. Choi BS, Mun Y. Policy alternatives analysis on army officer personnel management system. Korean Policy Sci Rev. 2006;10(1):51-78.

28. Yun JY, Ham OK, Cho IS, Lim JY. Effects of health promoting behaviors and mental health status of shift and non-shift nurses on quality of life. J Korean Public Health Nurs. 2012;26(2):268-79. https://doi.org/10.5932/ JKPHN.2012.26.2.268.

29. Kwag BG, Park JC, Lee W, Chang SH, Chun DH. The relationship between depression and health-related quality of life in Korean adult: Using 2014 Korea national health and nutrition examination survey data. Korean J Fam Pract. 2018;8(2):236-43. https://doi.org/10.21215/kjfp.2018.8.2.236.

30. U. S. Army. 2014 national depression awareness month. https://www. army.mil/article/135727/2014_national_depression_awareness_month. Accessed 29 Jan 2021.

31. Woo SY, Kim HJ, Kim BR, Ahn HC, Jang BN, Park EC. Support from superiors reduces depression in Republic of Korea military officers. BMJ Mil Health. 2020. https://doi.org/10.1136/jramc-2019-001343.

32. Angkaw AC, Haller M, Pittman JO, Nunnink SE, Norman SB, Lemmer JA, et al. Alcohol-related consequences mediating PTSD symptoms and mental health-related quality of life in OEF/OIF combat veterans. Mil Med. 2015;180(6):670-5. https://doi.org/10.7205/MILMED-D-14-00473.

33. Kim Y, Oh E. Health behavior and quality of life among Korean Navy. J Mil Nurs Res. 2015;33(1):53-66.

34. Park YR, Son YJ. Relationship of satisfaction with appearance, self-esteem, depression, and stress to health related quality of life in women across the lifespan. J Korean Acad Fundam Nurs. 2009;16(3):353.

\section{Publisher's Note}

Springer Nature remains neutral with regard to jurisdictional claims in published maps and institutional affiliations.
Ready to submit your research? Choose BMC and benefit from:

- fast, convenient online submission

- thorough peer review by experienced researchers in your field

- rapid publication on acceptance

- support for research data, including large and complex data types

- gold Open Access which fosters wider collaboration and increased citations

- maximum visibility for your research: over $100 \mathrm{M}$ website views per year

At BMC, research is always in progress.

Learn more biomedcentral.com/submissions 